\title{
Clinico-pathological study of malignant odontogenic tumours from a national referral centre
}

\author{
Hans Prakash Sathasivam ${ }^{*}$ (D), Chee Lynn Saw² and Shin Hin Lau ${ }^{1}$
}

\begin{abstract}
Background: Malignant odontogenic tumours are extremely rare tumours occurring within the jaws. Our study was performed to determine the demographic and clinico-pathological features of malignant odontogenic tumours amongst a multi-ethnic Asian population.

Methods: This was a retrospective cross-sectional study of malignant odontogenic tumours diagnosed at the Institute for Medical Research, Malaysia, from 2009 to 2019. All cases were independently reviewed and reclassified following the criteria set out in the latest edition of the World Health Organization 2017 reference text. Demographic and clinico-pathological data were recorded for each case.

Results: Twenty-four cases of malignant odontogenic tumours were identified. The patients' age ranged from 16 to 79 years with the mean age at diagnosis being 50.8 years $(S D=16.18)$. There was a male predominance $(66.7 \%)$ in this cohort of patients. The ethnic distribution appeared to reflect the Malaysian population with most cases seen amongst the Malay ethnic group (66.7\%). Ameloblastic carcinoma was the most frequently diagnosed malignant odontogenic tumour (45.8\%) and was also predominantly seen in males (90.9\%). All patients with clear cell odontogenic carcinoma were females. There was no obvious sex predilection in primary odontogenic carcinoma not otherwise specified (NOS). The mandible (79.2\%) was more frequently involved compared to the maxilla.

Conclusions: Diagnosis and management of malignant odontogenic tumours are challenging due to the rarity of these tumours. Our study has elucidated the clinico-pathological features of malignant odontogenic tumours seen in a multi-ethnic Asian population.
\end{abstract}

Keywords: Odontogenic tumour, Ameloblastic carcinoma, Odontogenic carcinoma, Malignant odontogenic tumour

\section{Background}

Odontogenic tumours (OT) are rare entities derived from epithelial, ectomesenchymal and/or mesenchymal components of the odontogenic (or tooth-forming) apparatus and make up less than $5 \%$ of all oral tumours $[1,2]$. The majority of OTs are located within bone (intra-osseous)
*Correspondence: hans@moh.gov.my

${ }^{1}$ Cancer Research Centre, Institute for Medical Research, National Institute of Health, Ministry of Health Malaysia, Setia Alam, Malaysia Full list of author information is available at the end of the article but there are some that occur in the soft tissue overlying tooth-bearing areas (peripheral/extra-osseous) [2].

The classification of odontogenic tumours has always been a much debated topic amongst head and neck pathologists with the nomenclature of specific odontogenic tumours changing over the years $[1,2]$. There have even been entities that were classified as tumours (keratocystic odontogenic tumour and calcifying cystic odontogenic tumour) in the previous edition of the World Health Organization (WHO) reference text being re-classified as cysts (odontogenic keratocyst \& calcifying

(c) The Author(s) 2021. Open Access This article is licensed under a Creative Commons Attribution 4.0 International License, which permits use, sharing, adaptation, distribution and reproduction in any medium or format, as long as you give appropriate credit to the original author(s) and the source, provide a link to the Creative Commons licence, and indicate if changes were made. The images or other third party material in this article are included in the article's Creative Commons licence, unless indicated otherwise in a credit line to the material. If material is not included in the article's Creative Commons licence and your intended use is not permitted by statutory regulation or exceeds the permitted use, you will need to obtain permission directly from the copyright holder. To view a copy of this licence, visit http://creativecommons.org/licenses/by/4.0/. The Creative Commons Public Domain Dedication waiver (http://creativeco mmons.org/publicdomain/zero/1.0/) applies to the data made available in this article, unless otherwise stated in a credit line to the data. 
odontogenic cyst) in view of their clinical behaviour as well as lack of convincing evidence to classify them as tumours $[1,2]$. The latest WHO reference text has also re-introduced "odontogenic carcinosarcoma" that was discarded in the previous edition of the WHO reference text $[1,2]$. Better understanding of the molecular profile of odontogenic tumours through a multi-omics approach may eventually enable improved classification of odontogenic tumours [3].

The vast majority of OTs are benign in nature and most studies have found that less than $10 \%$ of all odontogenic tumours are malignant [4-14]. However a recent study from Ethiopia on odontogenic tumours found that $19.6 \%$ of their cases were MOTs, suggesting ethnic and geographic variation may play a part in the aetiopathogenesis of MOTs [15]. There is very limited data regarding the clinico-pathological features of malignant odontogenic tumours (MOTs). Due to their relative rarity, the majority of information regarding MOTs is mostly based on individual case reports or small case-series or as a minor component of studies focusing on odontogenic tumours. Definitive diagnosis of MOTs may be difficult due to the relative lack of existing information on MOTs. Aside from that, the complex and ever-changing classification of these entities also adds an additional layer of difficulty in studying MOTs. Although there have been advances in molecular studies, diagnosis of MOTs is primarily based on the correlation of clinical, histopathological and radiological findings $[1,2]$. MOTs are believed to be locally aggressive with frequent recurrence mandating longterm follow up $[4,16,17]$.

The rarity of MOTs highlights the need for additional data to augment the existing literature regarding MOTs to further improve our understanding of these entities. At this point in time, there is limited data on the demographic and clinico-pathological features of MOTs in Malaysia. Our study was performed to add to the existing body of work and also reveal the demographic and clinico-pathological features of MOTs amongst Malaysian patients.

\section{Methods}

This was a cross-sectional study of malignant odontogenic tumours (MOTs) diagnosed at the Stomatology Unit of the Institute for Medical Research (IMR) Malaysia from 2009 until 2019. Cases were excluded if: i) there was incomplete data or; ii) the cases were recurrences. The following data were obtained from the archived records: age at diagnosis; sex; ethnicity; presenting complaint; smoking history; alcohol intake; histological diagnosis; site of tumour and treatment. Data were linkanonymised and recorded into a standardised proforma.
Cases were independently reviewed and classified by two oral \& maxillofacial pathologists (blinded to the original diagnosis) following criteria set out in the latest edition of the World Health Organization (WHO) reference text [2]. Briefly, archived haematoxylin and eosin (H\&E) stained sections of the cases identified from the database were retrieved and assessed. For cases where the archived H\&E stained slides were inadequate for diagnostic interpretation, new sections were cut from the relevant archived formalin-fixed paraffin-embedded (FFPE) blocks and stained with H\&E. A consensus meeting was held for discordant and complex cases.

Descriptive statistical analysis was performed using IBM SPSS Statistics for Windows version 26 (IBM Corp., Armonk, N.Y., USA). For continuous data, results were expressed as mean with standard deviation (SD). This study has favourable ethical opinion from the Malaysian Research Ethics Committee (NMRR-19- 673-4734) and complies with Malaysian legislation and guidelines.

\section{Results}

Thirty-two cases were identified from the database. However, eight cases were excluded due to incomplete data leaving only 24 cases for histopathological review. The demographic and clinico-pathologic features of the patients are listed in Table 1.

Table 1 Demographic and clinico-pathologic features of patients

\begin{tabular}{ll}
\hline Variable & Number of patients \\
\hline Age at diagnosis; Mean (SD) & 50.8 years (16.18) \\
Sex & 16 \\
Male & 8 \\
Female & \\
Ethnicity & 16 \\
Malay & 3 \\
Chinese & 2 \\
Indian & 1 \\
Iban & 1 \\
Bajau & 1 \\
Dusun & \\
Site & 5 \\
Maxilla & 19 \\
Mandible & \\
Diagnosis & 11 \\
Ameloblastic carcinoma & 3 \\
Clear cell odontogenic carcinoma & 9 \\
Primary intraosseous carcinoma NOS* & 1 \\
Ghost cell odontogenic carcinoma &
\end{tabular}

*NOS, not otherwise specified 
The age at diagnosis in this cohort ranged from 16 to 79 years of age with the majority $(83.3 \%)$ being $\geq 40$ years old at diagnosis peaking in the 5th \& 6th decades of life. The mean age for this group of patients was 50.8 years $(\mathrm{SD} \pm 16.18)$. The mean age for patients with ameloblastic carcinoma was lower at 47.0 years $(\mathrm{SD} \pm 17.83)$. There was a male predominance $(66.7 \%)$ with a $2: 1$ male to female ratio. The youngest patient was a 16-year old Malay male with ameloblastic carcinoma (AC). All but one patient $(95.8 \%)$ presented with a complaint of swelling whilst $83.3 \%$ of patients also complained of pain associated with the swelling.

Majority of cases involved the mandible (79.2\%). Ameloblastic carcinoma was the most frequently diagnosed MOT (45.8\%) and was predominantly seen in Malay males; there was only one female patient with AC. Two patients with AC developed pulmonary metastasis. All the clear cell odontogenic carcinomas seen were diagnosed in females. Primary intraosseous carcinoma not otherwise specified (PIOC-NOS) cases appeared to be almost equally distributed between the sexes (Table 2). Two of the PIOC-NOS were believed to have arisen from odontogenic cysts. One case of AC was preceded by an ameloblastoma. There was only one case of ghost cell odontogenic carcinoma. Overall, fifteen patients $(62.5 \%)$ has a history of smoking, whilst only seven patients $(29.2 \%)$ had a history of consuming alcoholic beverages. Nine $(81.8 \%)$ of the AC patients had a history of smoking, whilst only one $(9.1 \%)$ had a history of consuming alcoholic beverages. Relevant clinico-pathological information for each patient is displayed in Table 2.

Twenty patients were treated with intent to cure whilst two were treated palliatively and another two declined treatment. Surgery was the primary treatment modality for all cases treated with intent to cure. Two patients received additional post-operative radiotherapy as part of their treatment plan and one received surgery with concurrent chemoradiotherapy. Only sixteen patients $(66.7 \%)$ were alive and well on census date. The median follow-up time for these 16 patients was 41 months (inter-quartile range: 64.25 ). Time to

Table 2 Data of patient with malignant odontogenic tumours (MOTs)

\begin{tabular}{|c|c|c|c|c|c|}
\hline Case & Age range (years) & Ethnicity & Site & Diagnosis & Treatment \\
\hline 1 & $50-59$ & Malay & Mandible & Ameloblastic carcinoma & Surgery \\
\hline 2 & $20-29$ & Malay & Mandible & Ameloblastic carcinoma & Surgery \\
\hline 3 & $40-49$ & Malay & Mandible & Ameloblastic carcinoma & Surgery \\
\hline 4 & $60-69$ & Malay & Mandible & Clear cell odontogenic carcinoma & Surgery \\
\hline 5 & $50-59$ & Dusun & Maxilla & Primary intraosseous carcinoma NOS & Surgery \\
\hline 6 & $40-49$ & Chinese & Mandible & Clear cell odontogenic carcinoma & Surgery \\
\hline 7 & $50-59$ & Malay & Mandible & Primary intraosseous carcinoma NOS & Surgery \\
\hline 8 & $50-59$ & Indian & Mandible & Primary intraosseous carcinoma NOS & Surgery \\
\hline 9 & $20-29$ & Iban & Mandible & Ameloblastic carcinoma & Surgery \\
\hline 10 & $40-49$ & Malay & Mandible & Ameloblastic carcinoma & Palliative \\
\hline 11 & $70-79$ & Indian & Maxilla & Ameloblastic carcinoma & Palliative \\
\hline 12 & $40-49$ & Bajau & Maxilla & Primary intraosseous carcinoma NOS & Surgery \\
\hline 13 & $40-49$ & Malay & Maxilla & Primary intraosseous carcinoma NOS & Surgery \\
\hline 14 & $60-69$ & Malay & Mandible & Primary intraosseous carcinoma NOS & Surgery \\
\hline 15 & $50-59$ & Malay & Mandible & Primary intraosseous carcinoma NOS & Surgery \\
\hline 16 & $50-59$ & Malay & Mandible & Ameloblastic carcinoma & $\begin{array}{l}\text { Surgery and concurrent } \\
\text { chemoradiotherapy }\end{array}$ \\
\hline 17 & $70-79$ & Malay & Maxilla & Clear cell odontogenic carcinoma & Declined \\
\hline 18 & $60-69$ & Malay & Mandible & Ameloblastic carcinoma & Declined \\
\hline 19 & $40-49$ & Malay & Mandible & Ameloblastic carcinoma & Surgery and radiotherapy \\
\hline 20 & $10-19$ & Malay & Mandible & Ameloblastic carcinoma & Surgery \\
\hline 21 & $40-49$ & Malay & Mandible & Primary intraosseous carcinoma NOS & Surgery \\
\hline 22 & $70-79$ & Chinese & Mandible & Ghost cell odontogenic carcinoma & Surgery \\
\hline 23 & $50-59$ & Malay & Mandible & Ameloblastic carcinoma & Surgery \\
\hline 24 & $20-29$ & Chinese & Mandible & Primary intraosseous carcinoma NOS & Surgery and radiotherapy \\
\hline
\end{tabular}




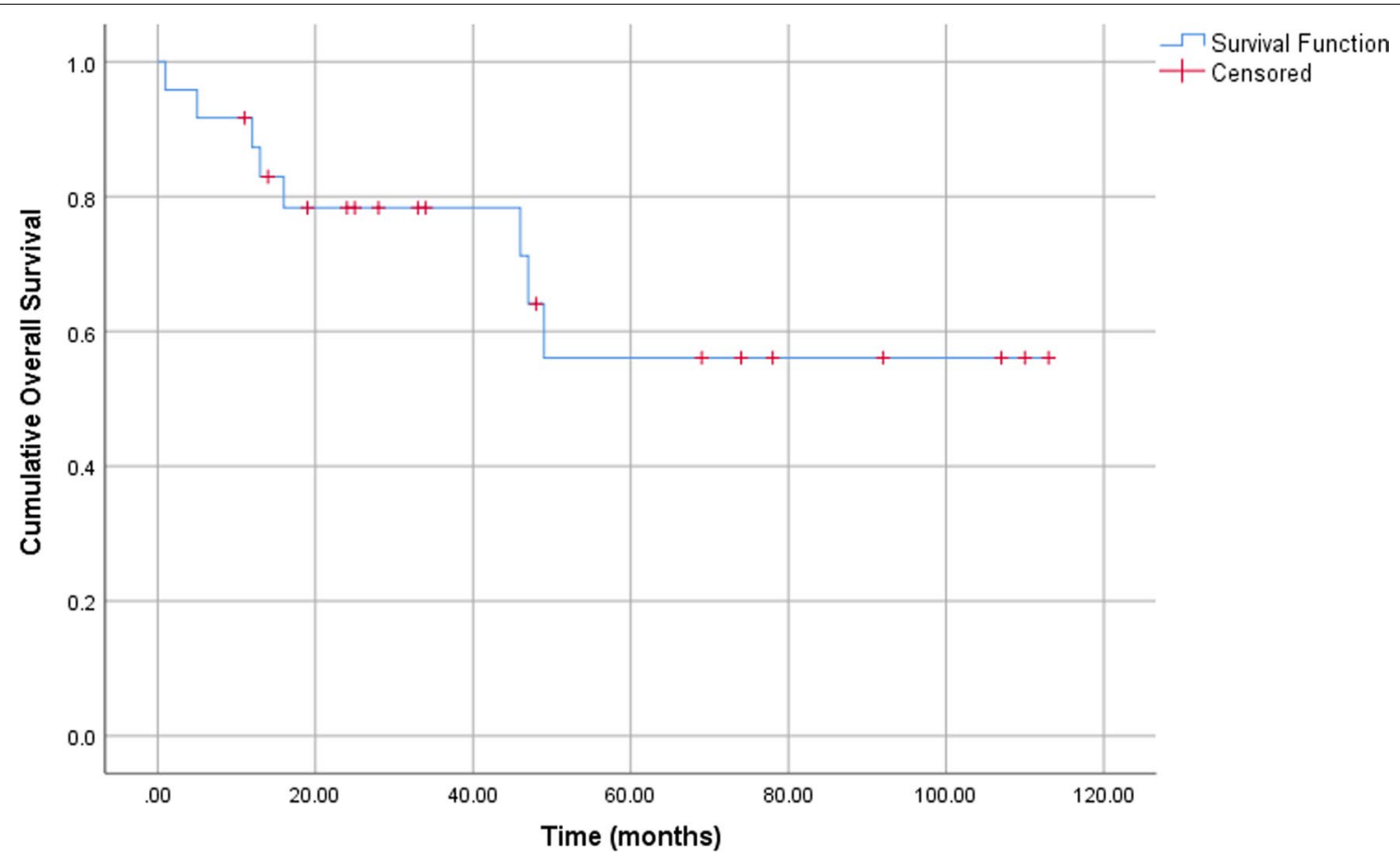

Fig. 1 Kaplan-Meier curve for time to event analysis looking at overall survival of patients with MOT

event analysis looking at the overall survival of patients with MOTs is shown in Fig. 1.

\section{Discussion}

Malignant odontogenic tumours are extremely rare. A pooled analysis on the global incidence of odontogenic tumours by Avelar et. al. (2011) found that only around $4 \%$ of odontogenic tumours were malignant [18]. A recently published Malaysian study on odontogenic tumours made up of 173 cases had only two (1.2\%) cases of MOT [5]. Malignant odontogenic tumours can be broadly classified into odontogenic carcinomas, odontogenic sarcomas and odontogenic carcinosarcoma. Although odontogenic carcinosarcomas were reintroduced in the latest edition of the WHO reference text on classification of head and neck tumours, they are extremely rare entities [2]. Over the 11-year period of our study, there were no cases of odontogenic sarcomas or odontogenic carcinosarcomas, highlighting the relative rarity of such lesions compared to odontogenic carcinomas.

Although MOTs can be seen in any age group, the odontogenic carcinomas frequently occur in patients aged $>40$ years and this trend is seen in our study as well with more than $80 \%$ of cases occurring in those aged $\geq 40$ years $[2,12,15,18]$. The mean age of our patients ( 50.8 years; $\mathrm{SD} \pm 16.18$ ) was also similar to most other studies focusing on odontogenic carcinomas as there were no sarcomas or carcinosarcomas in our cohort $[17,19,20]$. The mean age for patients with AC was even lower at 47.0 years $(\mathrm{SD} \pm 17.83)$ similar to the findings of the systematic review by Deng et al. [20]. The male predominance seen in our study is also in line with most other published works, though there are some studies that have reported either no sex predilection or a female preponderance [7-9, 12, 17-19, 21, 22]. Interestingly, when looking at the different MOTs, a striking male preponderance was seen in ACs whilst all the patients diagnosed with $\mathrm{CCOC}$ were females. A recent systematic review highlighted that ACs are more frequently seen in males $(72.0 \%)$ with a male to female ratio of $2.58: 1$ [20]. The frequent involvement of the mandible in our study is similar to most other studies in the Asian population [7, $17,20,23]$.

The overall ethnic distribution of MOT patients in our study appears to reflect the general ethnic distribution of the Malaysian population, however there does seem to be an overwhelmingly high incidence of ameloblastic carcinoma among Malay patients with only two nonMalay patient having AC. This could be due to genetic predisposition, however further longitudinal studies made up of a larger number of patients is necessary before such conclusions can be made. The role of smoking and alcohol consumption in the aetiopathogenesis of $\mathrm{AC}$ is still unclear as these tumours usually arise intraosseously and are therefore not exposed to carcinogens 
with perhaps the exception of $\mathrm{AC}$ arising from peripheral ameloblastoma. On another note, smoking and alcohol consumption history is usually self-reported and as such the veracity of the information provided itself is fraught with ambiguity [24].

The two most frequently encountered MOTs as reported in the literature are ameloblastic carcinoma (AC) and primary intra-osseous carcinoma NOS (PIOCNOS) $[6,7,9,19,21,22]$. Ameloblastic carcinoma has been considered to be the malignant counterpart of the ameloblastoma characterized by cytological atypia and the ability to metastasize and is the most frequently encountered MOT. Ameloblastic carcinomas also have been reported to have BRAF V600E mutations similar to that seen in ameloblastomas alluding to the possibility that ACs arise from ameloblastomas [25]. Our findings suggest that the majority of ACs arise de novo as only one case in our cohort had a history of pre-existing ameloblastoma. Though some ACs may indeed arise from ameloblastomas it is quite difficult to prove this conclusively and it is currently believed that the large proportion of ACs arise de novo [2]. The previous version of the WHO reference text sub-typed ACs into either; (1) primary type, (2) secondary type (dedifferentiated) intraosseous or (3) secondary type (dedifferentiated), peripheral. This sub-typing was dropped in the recent edition of the WHO reference text possibly due to the fact that as yet, there is no concrete evidence on the histogenesis of these lesions, the possible role of precursor lesions in the aetiopathogenesis, and the clinical significance of subtyping $[1,2]$.

Primary intra-osseous carcinoma NOS (PIOC-NOS) was previously sub-typed either as (1) a solid tumour invading marrow spaces and inducing bone resorption, (2) a squamous carcinoma arising from the lining of an odontogenic cyst or (3) a squamous cancer arising in association with other benign odontogenic tumours [1]. This sub-typing however has been dropped from the latest edition of the WHO reference text possibly due to the uncertainty surrounding the clinical significance of such sub-typing [2]. At this point in time, there is insufficient evidence that sub-typing can reliably predict clinical outcome or overall survival. One difficulty associated with the diagnosis of PIOC-NOS is that once the tumour perforates the cortex and merges with the oral epithelium, distinguishing it from a squamous cell carcinoma arising from the oral mucosa can be challenging especially if there are no obvious odontogenic precursor lesions. Primary intra-osseous carcinoma NOS is also a diagnosis of exclusion having ruled out other carcinomas especially metastatic lesions.

All three clear cell odontogenic carcinomas (CCOC) in our study were female patients which is consistent with pooled findings from other studies [2, 26-28]. One of the differential diagnosis for $\mathrm{CCOC}$ is the hyalinizing clear cell carcinoma (HCCC) of the salivary gland which may occur in the jaws $[2,29]$. Due to the overlapping clinical, pathological and immunophenotypic patterns, confidently distinguishing between these entities is at times rather difficult. Peripheral palisading in the epithelial islands and the location are thought to be helpful in separating CCOC from HCCC $[29,30]$. A large proportion of CCOC have also been shown to have EWSR1 rearrangements, similar to that found in clear cell salivary gland carcinoma, suggesting that these tumours despite their differing locations, are somewhat related [2, 31, 32].

A major limitation of our study was the inability to obtain complete clinical, radiographic and long-term outcome data for our patients due to the study design and reliance on retrospective data. Very little is known regarding the aetiopathogenesis MOTs with most believed to arise de-novo though a proportion of cases also do arise from pre-existing benign lesions such as odontogenic cysts or tumours [2, 33-36]. In our cohort of patients, two cases of PIOC-NOS were believed to have arisen from the epithelial lining of odontogenic cysts and one case of ameloblastic carcinoma was thought to have been preceded by an ameloblastoma. In many cases proving that the malignant tumour originated from a pre-existing benign lesion is extremely difficult. It must be emphasized that diagnosis of malignant odontogenic tumours is challenging; due to its' rarity and also due to the overlapping features with benign odontogenic tumours as well as other tumours in the maxillofacial region.

\section{Conclusions}

The characterisation, classification and understanding of MOTs will continue to develop as more cases are reported in the literature. This study has added valuable clinico-pathological information on malignant odontogenic tumours that are extremely rare, with scarcity of data in the existing literature especially in the Malaysian setting.

With the advent of molecular profiling, an additional dimension has been added to help further characterise these tumours and perhaps pave the way for improved management of patients with malignant odontogenic tumours.

\section{Abbreviations}

AC: Ameloblastic carcinoma; CCOC: Clear cell odontogenic carcinoma; FFPE: Formalin-fixed paraffin-embedded; H\&E: Haematoxylin and eosin; HCCC: Hyalinizing clear cell carcinoma; IMR: Institute for Medical Research; MOT: Malignant odontogenic tumour; NOS: Not otherwise specified; OT: Odontogenic tumour; PIOC-NOS: Primary intraosseous carcinoma not otherwise specified; SD: Standard deviation; WHO: World Health Organization. 


\section{Acknowledgements}

We would like to thank the Director-General of Health Malaysia for his permission to publish this article.

\section{Authors' contributions}

HPS: Proposed the idea, designed the study, contributed to data collection \& analysis and wrote the manuscript. SCL: Contributed to data analysis and critically reviewed the manuscript. LSH: Proposed the idea, contributed to data collection and critically reviewed the manuscript. All authors read and approved the final version of the manuscript.

\section{Funding}

Not applicable.

\section{Availability of data and materials}

The datasets used and/or analysed during the current study are available from the corresponding author on reasonable request.

\section{Ethics approval and consent to participate}

This study was approved by Malaysian Research Ethics Committee (NMRR-19673-4734) and complies with Malaysian legislation and guidelines. Permission was also granted by the committee and Director of the Institute for Medical Research to access the tissue $\&$ data.

\section{Consent for publication}

Not applicable.

\section{Competing interests}

Not applicable.

\begin{abstract}
Author details
${ }^{1}$ Cancer Research Centre, Institute for Medical Research, National Institute of Health, Ministry of Health Malaysia, Setia Alam, Malaysia. ${ }^{2}$ Penang Health Services, Ministry of Health Malaysia, Georgetown, Malaysia.
\end{abstract}

\section{Received: 5 July 2020 Accepted: 15 December 2020}

Published online: 18 March 2021

\section{References}

1. Barnes L, Eveson JW, Reichart P, Sidransky D, editors. Pathology and genetics of head and neck tumours. Lyon: World Health Organization, IARC; 2005.

2. El-Naggar AK, Chan JKC, Grandis JR, Takata T, Slootweg PJ, editors. WHO classification of head and neck tumours. Lyon: International Agency for Research on Cancer; 2017.

3. Duarte-Andrade FF, Vitório JG, Pereira TSF, Gomes CC, Gomez RS. A review of the molecular profile of benign and malignant odontogenic lesions. Oral Surg Oral Med Oral Pathol Oral Radiol. 2020;129(4):357-68.

4. Mosqueda Taylor A, Meneses Garcia A, Ruiz Godoy Rivera LM, Suarez Roa Mde L, Luna Ortiz K. Malignant odontogenic tumors. A retrospective and collaborative study of seven cases. Med Oral. 2003;8(2):110-21.

5. Ismail S, Saw CL. A clinicopathologic study of 173 odontogenic tumours in Northern Peninsular Malaysia (2007-2014). Malays J Pathol. 2018;40(2):129-35.

6. Sekerci AE, Nazlim S, Etoz M, Deniz K, Yasa Y. Odontogenic tumors: a collaborative study of 218 cases diagnosed over 12 years and comprehensive review of the literature. Med Oral Patol Oral Cir Bucal. 2015;20(1):e34-44

7. Jing W, Xuan M, Lin Y, Wu L, Liu L, Zheng X, Tang W, Qiao J, Tian W. Odontogenic tumours: a retrospective study of 1642 cases in a Chinese population. Int J Oral Maxillofac Surg. 2007;36(1):20-5.

8. da-Costa DO, Mauricio AS, de-Faria PA, da-Silva LE, Mosqueda-Taylor A, Lourenco SD. Odontogenic tumors: a retrospective study of four Brazilian diagnostic pathology centers. Med Oral Patol Oral Cir Bucal. 2012;17(3):389-94.

9. Siriwardena BSMS, Tennakoon TMPB, Tilakaratne WM. Relative frequency of odontogenic tumors in Sri Lanka: Analysis of 1677 cases. Pathol Res Pract. $2012 \cdot 208(4) \cdot 225-30$
10. Ahire M, Tupkari J, Chettiankandy T, Thakur A, Agrawal R. Odontogenic tumors: A 35-year retrospective study of 250 cases in an Indian (Maharashtra) teaching institute. Indian J Cancer. 2018;55(3):265-72.

11. Goteti S. Odontogenic tumors: a review of 675 cases in Eastern Libya. Niger J Surg. 2016;22:37-40.

12. Mascitti M, Togni L, Troiano G, Caponio VCA, Sabatucci A, Balercia A, Rubini C, Lo Muzio L, Santarelli A. Odontogenic tumours: a 25-year epidemiological study in the Marche region of Italy. Eur Arch Otorhinolaryngol. 2020:277(2):527-38.

13. Lima-Verde-Osterne R, Turatti E, Cordeiro-Teixeira R, Barroso-Cavalcante $R$. The relative frequency of odontogenic tumors: A study of 376 cases in a Brazilian population. Medicina oral, patologia oral y cirugia bucal. 2017;22(2):e193-200

14. Siriwardena BSMS, Crane H, O'Neill N, Abdelkarim R, Brierley DJ, Franklin CD, Farthing PM, Speight PM, Hunter KD. Odontogenic tumors and lesions treated in a single specialist oral and maxillofacial pathology unit in the United Kingdom in 1992-2016. Oral Surg Oral Med Oral Pathol Ora Radiol. 2019:127(2):151-66.

15. Kebede B, Tare D, Bogale B, Alemseged F. Odontogenic tumors in Ethiopia: eight years retrospective study. BMC Oral Health. 2017:17(1):54.

16. Goldenberg D, Sciubba J, Koch W, Tufano RP. Malignant odontogenic tumors: a 22-year experience. Laryngoscope. 2004;114(10):1770-4.

17. Chaisuparat R, Sawangarun W, Scheper MA. A clinicopathological study of malignant odontogenic tumours. Histopathology. 2012;61(1):107-12.

18. Avelar RL, Primo BT, Pinheiro-Nogueira CB, Studart-Soares EC, de Oliveira RB, Romulo de Medeiros J, Hernandez PAG. Worldwide incidence of odontogenic tumors. J Craniofac Surg. 2011:22(6):2118-23.

19. Martinez Martinez M, Mosqueda-Taylor A, Carlos R, Delgado-Azanero W, de Almeida OP. Malignant odontogenic tumors: a multicentric Latin American study of 25 cases. Oral Dis. 2014;20(4):380-5.

20. Deng L, Wang R, Yang M, Li W, Zou L. Ameloblastic carcinoma: clinicopathological analysis of 18 cases and a systematic review. Head Neck. 2019:41(12):4191-8.

21. Soyele OO, Effiom OA, Lawal AO, Nwoga MC, Adebiyi KE, Aborisade A, Olatunji AS, Olawuyi AB, Ladeji AM, Okiti RO, et al. A multi-centre evaluation of malignant odontogenic tumours in Nigeria. Pan Afr Med J. 2019;33:18

22. Lawal $\mathrm{AO}$, Soyele $\mathrm{OO}$, Akinyamoju $\mathrm{AO}$. A retrospective study of 21 cases of malignant odontogenic tumours from two tertiary health centres in Nigeria. Pan Afr Med J. 2015;20:371.

23. Luo H-Y, Li T-J. Odontogenic tumors: A study of 1309 cases in a Chinese population. Oral Oncol. 2009:45(8):706-11.

24. Alberg AJ, Worley ML, Tooze JA, Hatcher JL, Carpenter MJ, Day TA, Sullivan CA, Warren GW, Sterba KR, Weaver KE. The validity of self-reported recent smoking in head and neck cancer surgical patients. Otolaryngol Head Neck Surg. 2015;153(6):990-5.

25. Diniz MG, Gomes CC, Guimarães BV, Castro WH, Lacerda JC, Cardoso SV, de Faria PR, Dias FL, Eisenberg AL, Loyola AM, et al. Assessment of BRAFV600E and SMOF412E mutations in epithelial odontogenic tumours. Tumour Biol. 2015;36(7):5649-53.

26. Li TJ, Yu SF, Gao Y, Wang EB. Clear cell odontogenic carcinoma: a clinicopathologic and immunocytochemical study of 5 cases. Arch Pathol Lab Med. 2001:125(12):1566-71.

27. Muramatsu T, Hashimoto S, Inoue T, Shimono M, Noma H, Shigematsu T. Clear cell odontogenic carcinoma in the mandible: histochemical and immunohistochemical observations with a review of the literature. J Oral Pathol Med. 1996;25(9):516-21.

28. Brandwein M, Said-Al-Naief N, Gordon R, Urken M. Clear cell odontogenic carcinoma: report of a case and analysis of the literature. Arch Otolaryngol Head Neck Surg. 2002;128(9):1089-95.

29. Bilodeau EA, Hoschar AP, Barnes EL, Hunt JL, Seethala RR. Clear cell carcinoma and clear cell odontogenic carcinoma: a comparative clinicopathologic and immunohistochemical study. Head Neck Pathol. 2011:5(2):101-7.

30. Richardson MS, Muller S. Malignant odontogenic tumors: an update on selected tumors. Head Neck Pathol. 2014:8(4):411-20.

31. Bilodeau EA, Weinreb I, Antonescu CR, Zhang L, Dacic S, Muller S, Barker B, Seethala RR. Clear cell odontogenic carcinomas show EWSR1 rearrangements: a novel finding and a biological link to salivary clear cell carcinomas. Am J Surg Pathol. 2013;37(7):1001-5. 
32. Antonescu CR, Katabi N, Zhang L, Sung YS, Seethala RR, Jordan RC, Perez-Ordoñez B, Have C, Asa SL, Leong IT, et al. EWSR1-ATF1 fusion is a novel and consistent finding in hyalinizing clear-cell carcinoma of salivary gland. Genes Chromosomes Cancer. 2011;50(7):559-70.

33. Sathasivam HP, Lau SH, Khalid N. Primary intra-osseous squamous cell carcinoma arising from an odontogenic cyst: a case report. Arch Orofac Sci. 2017;12(1):55-9.

34. Bodner L, Manor E, Shear M, van der Waal I. Primary intraosseous squamous cell carcinoma arising in an odontogenic cyst: a clinicopathologic analysis of 116 reported cases. J Oral Pathol Med. 2011;40(10):733-8.

35. Morita T, Yamashiro M, Kayamori K, Mizutani M, Nakakuki K, Michi

Y, Uzawa N, Izumo T, Harada K. Primary intraosseous squamous cell carcinoma derived from a maxillary cyst: A case report and literature review. Mol Clin Oncol. 2016;4(4):553-8.

36. Takahashi H, Takaku Y, Kozakai A, Otsuru H, Murata Y, Myers MW. Primary intraosseous squamous cell carcinoma arising from a dentigerous cyst of the maxillary wisdom tooth. Case Rep Oncol. 2020;13(2):611-6.

\section{Publisher's Note}

Springer Nature remains neutral with regard to jurisdictional claims in published maps and institutional affiliations.
Ready to submit your research? Choose BMC and benefit from:

- fast, convenient online submission

- thorough peer review by experienced researchers in your field

- rapid publication on acceptance

- support for research data, including large and complex data types

- gold Open Access which fosters wider collaboration and increased citations

- maximum visibility for your research: over $100 \mathrm{M}$ website views per year

At BMC, research is always in progress.

Learn more biomedcentral.com/submissions 